\title{
National Guarantor for the Rights of People Detained or Deprived of their Liberty and Vulnerability of the Elderly
}

\author{
Giovanna Fanci \\ Researcher in Sociology \\ Department of Law \\ University of Macerata \\ Piaggia dell'Università, no. 2 \\ 62100 Macerata (MC) \\ Italy
}

\begin{abstract}
The article reflects on the institution of Italian National Guarantor of the rights of persons detained or deprived of their liberty (NGDL), limited to the health area and, in detail, to the protection of liberty of the elderly population. The study starts with the description of duties and functions of the Guarantor as foreseen by the institutive norm; it then reconstructs the debate on the theme of ageism and illustrates the Italian care'ssystem. The joining link between these two parts is determined in the textual study of the annual reports to the Parliament and in the examination of the visits carried out at residences for the elderly. This path will show that the role of guaranteeing remains incomplete. What firstly appeared to be an opportunity to strengthen the mechanisms of protection of various conditions of fragility, at the moment, needs a further period of growth and consolidation.
\end{abstract}

Keywords: Ageism; care; Italianregionalisation; National guarantor; structures.

\section{Introduction}

The establishment of an independent guaranteeing institution for the protection of personal liberty in Italy is quite recent. Its creation aims to enrich the institutional scenario of an autonomous figure in support of the public administration. The Guarantor was designated as national mechanism for the prevention of torture in all places of liberty'sdeprivation, expanding its sphere of competence which now includes various detention facilities: therapeutic communities or homes for the elderly, places for involuntary treatment, for home detention and for interrogatories of the investigating authorities.

The present work aims to contribute to the debate on National Guarantor of the rights of persons detained or deprived of their liberty (NGDL) within the Italian State through the observation of its institutional activity. It is not the holder of decision-making powers or, obviously, of sanctioning powers and its reports do not have binding effects on those institutions to which they are addressed. Its task of avoiding acts that are degrading human dignity is executed, therefore, through the submission of recommendations to public institutions, the collection of complaints from who are in condition of restriction and the presentation of an annual report to the Parliament. Competenceand informality of its interventions are the distinguishing aspects of its action. Placing itself «at the halfway point» between institutions and «not free» individual condition, it can perceive threats of unjust treatments from those who have the mandate, but it can also highlight problems in management and organisation.

There are several reasons for which this analysis is limited to the area of health and, in detail, to the protection of the elderly'sliberty. First of all, the institutional and scientific attention is mainly focused on the penal area and on the migratory flows. Another reason is related to the Italian demographic trend towards an ageing population and to the change in family organisation such as to perceive the elderly care as an emerging need to which institutions must respond.

In light of a polysemic definition of the concept of personal liberty, this essay suggests the analyses of the activity of NGDL with regard to the protection of the elderly housed in residences. The examination of the visits carried out will show that the role of guaranteeing remains incomplete. What firstly appeared to be an opportunity to strengthen the mechanisms of protection of various fragility conditions needs a further period of growth and consolidation: the establishment of the NGDL represents a procedural fulfilment of an international obligation and, therefore, an opportunity to improve forms and practices of individual treatment. 


\section{The establishment of the Italian National Guarantor for the Rights of People Detained or Deprived of their Liberty}

After a long and sporadic parliamentary debate, which began in 1997, Italy came to the establishment of the NGDL at the end of a path made of different stages ${ }^{1}$. After Italian ratification of the Optional Protocol to the Convention against Torture of the United Nations ${ }^{2}$ the NGDL was introduced in February 2014, in force from April $2015^{3}$, and became operational in March 2016 after itscollege'snomination and itsoffice'sformation. The Ministerial Decree establishes a control power that concerns criminal detention facilities (penitentiary institutions), hospitalisation facilities (therapeutic communities and houses for the elderly), places for involuntary treatment, for home detention, for interrogatories of the investigating authorities and immigration centres ${ }^{4}$. In this way, respect for human dignity is required as a supreme good that also limits public action "in the name of a single value, the liberty of individuals" (Bin, 2004: 24).

Given the guarantee of autonomy ensured by its own team, its supervisory role is expressed through the power of visit, even without forewarning, to the different places of liberty'sdeprivation. At the end of each inspection, the Guarantor draws up a report containing observations and possible solicitations. Moreover, as «independent national mechanism», it coordinates the regional guarantors suggesting common practices and procedures.

After an initial period, the Guarantor, in its first public act, outlines its tasks as follows:

"The Guarantor is a non-governmental and independent public institution; it is not a judicial body but acts in a complementary way with the magistrature; it is a preventive mechanism that intervenes in advance to reduce the problematic profiles of every situation; it acts on its own initiative and independently; it monitors all areas of liberty'sdeprivation through a regular system of visits; it has free and unannounced access to the places, independently chosen, to the information and to the persons with whom it can carry out reserved interviews without visual or auditory control"(NGDL, 2017: 26-27).

As already mentioned, areas of intervention are heterogeneous and correspond to the penal, security, migration and health fields. They refer to conditions characterized by limitation of movement and the Guarantor's institution has been established to prevent harmful situations:

"It is not an Ombudsman or an inspection mechanism because it is predominantly an independent body for regular monitoring. [...] Naturally, the Guarantor is not endowed with sanctioning powers because they would be in contrast with its configuration as a cooperative mechanism"(NGDL, 2019: 215).

Health is a new topicconnected with an intrinsic vulnerability that requires protection: it's the case of the involuntary treatment - consisting in a forced hospitalisation of the patient that manifests psychic or behavioural alterations and refuses medical treatment - and the hospitalisation of elderly or disabled in public facilities or in those in agreement with the NHS that provide assistance. It is difficult to assess whether the willingness to seek treatment is conscious or it is determined by the physical and emotional distress of the patient's condition, as well as whether it is driven by the influence of the family environment or by various contingencies:

"The theme acquires a particular ethical importance for two reasons: the first, because people in these structures are generally those highly vulnerable, at high risk of being subjected to the improper use of coercive practices or to negligence of the staff; the second reason is for the State's responsibility to protect the rights of these people. The purpose is to set up round tables for the launch of social and health policies based on a common strategy to prevent abuse and violation of fundamental rights, and for the identification of a local network that maps these structures, for the consolidation and diffusion of good practices" (NGDL 2017: 138).

\section{Ageism: betweendiscrimination and restrictionofthelibertyofself-determination.}

In recent years, the care of the elderly has become a central theme of public policies for various reasons, of political and economic nature.The population'sageing is a long-term trend that began some decades ago in Europe and will be of significant importance even in the decades to come. This tendency is evident in the population'stransformation in relation to growing number of elderly people and decreasing number of working age population. Constantly low birth-

\footnotetext{
${ }^{1}$ The launch of the experience of the territorial Guarantors and the Action Plan developed by the Italian Ministry of Justice represent the response to the «pilot judgment» of the Strasbourg Court in the case Torreggiani and other c. Italy

https://hudoc.echr.coe.int/eng\#\{\%22fulltext\%22:[\%221\%22CASE\%20OF\%20TORREGGIANI\%20AND\%20OTHERS\%20v.\%20ITALY\\%22\%22],\%22documentcollectionid2\% 22:[\%22GRANDCHAMBER\%22,\%22CHAMBER\%22],\%22itemid\%22:[\%22001-116248\%22]\}

${ }^{2}$ Cf. https://www.ohchr.org/EN/ProfessionalInterest/Pages/OPCAT.aspx

${ }^{3}$ Cf.http://www.gazzettaufficiale.it/atto/vediMenuHTML;jsessionid=-55WfxLNzoIQJ1bTOJjiRQ_.ntc-as3-guri2b?atto.dataPubblicazioneGazzetta=2015-03-

$31 \&$ atto.codiceRedazionale $=15 \mathrm{G} 00050 \&$ tipoSerie $=$ serie_generale $\&$ tipoVigenza $=$ originario

4 This category includes first aid and reception centres, reception centres and centres for asylum seekers and centres for identification and expulsion. Cf. http://www.interno.gov.it/it/temi/immigrazione-e-asilo/sistema-accoglienza-sul-territorio/centri-limmigrazione
} 
rate $^{5}$ and longer life expectancy ${ }^{6}$ are changing the demographic characteristics of citizens. Over the last ten years, the growth fluctuates between 4.9 percentage points in Malta and 0.1 percentage points in Luxembourg. In the last decade (2007-2017) there has been an increase of 2.4 percentage points throughout the EU-28 area (Eurostat, 2018).

According to Eurostat' studies ${ }^{7}$, the EU-28 population will grow to a peak of 528.6 million around the 2050, to gradually decrease to 518.8 million by 2080 . Over the next few decades, the numerous "baby boomers" will be swelling the ranks of the elderly. However, by 2080 the pyramid will more and more take the shape of a block, considerably shrinking to the centre (around 45-54 years). The percentage of working age population in the EU-28 area will decrease, while the relative number of pensioners will increase: this will create a greater burden for the working age population, who will have to provide for the social costs of the ageing citizens and for a series of services connected to them. Another difficult aspect concerns the progressive advancement of the age of the same elderly population: the number of individuals aged 80 or over in the EU-28 population is expected to be higher than its double between 2017 and 2080 , from $5.5 \%$ to $12.7 \%^{8}$.

What has been said so far explains the reason why the care of the elderly has become central, not only in the political debate (with regard to the management and reorganisation of public services and the necessity to respond to the pressing needs of containing public spending) [Cortijo, McGinnis\&Sisli-Ciamarra, 2019], but above all in the social sciences that focus on the effects of the progressive ageing on social dynamics and interaction practices.

The presence of people over 65 determines greater closeness to that phase of life in which physical conditions deteriorate and this can cause the onset of a state of fear. There is a tendency towards the stigmatisation of "seniors": "as being "different from us" (Evans\&Montvillo, 2018). These feelings are linked to the change in the family's structure and its mobility: household is increasingly characterised by the absence of grandparents, who live an existence far from that of their children and grandchildren. Over the years, these factors have caused the spread of stereotypes according to which people over 65 are old and inflexible; they do not understand and can no longer experience pleasures of any kind: it is as if the lack of interaction and daily sharing of spaces had cognitively distanced generations (Kennedy\&Montvillo, 2000). In literature, the theme is connected with the definition of ageism (Butler, 1975), a form of discrimination, often hidden, carried out by a group of an age towards a group of another age and consisting in the low propensity to care and tolerance.

This form of discrimination has represented the focus of many discussions:

"When older adults are told that they 'don't look their age', 'look good for their age', or are 'young at heart', it is typically perceived as a complement. However, embedded in these remarks is the assumption that the youth is inherently better than old age. This implicit association between 'old' and 'bad' is strongly endorsed by both younger and older adults" (Barber, Tan 2018: 115).

The World Health Organization (WHO $)^{9}$ denounces that this discriminatory trend is more "normalised" than other forms such as racism or sexism because a large part of the community does not have full awareness of it ${ }^{10}$, although it is a condition that will affect everyone, sooner or later (Palmore, 1999).

Here we intend to draw attention to those clichés addressed to more mature people; they are marginalised through insidious social practices that can produce harmful effects on the general conditions of well-being (Levy\& MacDonald, 2016); moreover, victims are far from the world of work and, sometimes, little followed by social services. These wayswill probably condition the dynamics of interaction by imposing a negative approach on the future well-being improvement and the «old person» sociality from a double point of view:

from his side, where future is in decline (Brothers, Gabrian, Wahl \& Diehl 2016; Brothers, Chui \& Diehl, 2014) and from actors who do not imagine the possibility of building a positive social network. This is evident in some therapeutic relationships: health care professionals tend to choose treatment strategies taking into account the patient's life expectancy. This hypothesis is confirmed by a recent research on therapeutic choices: in case of breast cancer, there is a tendency to remove it in women older than 70 years and to treat it with radiotherapy for the younger ones (Di Rosa et al, 2018).

\footnotetext{
${ }^{5}$ Constantly low fertility levels have contributed to the ageing of the population for many years and the lower number of births has led to a decline in the percentage of young people in the total population. This process, known as "base ageing" of the population pyramid, can be observed in the narrowing of the pyramid base of the EU-28 population between 2002 and 2017 (Eurostat. Statistics Explained, 2018).

${ }^{6}$ This phenomenon is also known as "vertex ageing" of the population pyramid (Eurostat. Statistics Explained, 2018).

${ }^{7}$ Cf. https://ec.europa.eu/eurostat.

${ }^{8}$ A similar demographic trend can be observed overseas (Migliaccio, 2019).

${ }^{9}$ Cf. https://www.who.int/bulletin/volumes/96/4/17-202424/en/.

${ }^{10} \mathrm{Cf}$. https://www.who.int/ageing/ageism/en/.
} 
Ageism can become an interpretative key to social dynamics even within residences in which the conditions of physical and, sometimes, mental vulnerability of the guests can provoke marginalisation and/or denigration behaviour. International institutions have shown an unexpected sensitivity towards this problem that is considered fundamental for the development of communities. The General Assembly of the United Nations established a working group, "Open Ended Group on Ageing", which has the task of examining the rights system of older people and identifying any regulatory gaps ${ }^{11}$. Among the areas of action, there is also the one concerning the recognition and diffusion of practices to prevent abuse within the structures. For example, a member of this consortium is T.A.M "TelefonoAnzianiMaltrattati", an Italian telephone service for ill-treated elderly people ${ }^{12}$.

\section{Italian care system for the elderly: care homes.}

Now, it seems appropriate to analyse Italian care system for the elderly. It shows a common trend in most European countries: the main source is represented by family members, cohabitants or not, even in Scandinavian countries where public intervention is very strong (Ranci, Pavolini 2015). However, this consideration would be defective if it were not integrated with the analysis of other factors which, in reality, contribute to the development of a rather complex picture. They are linked to the transformation of the family model, also from the point of view of its organisation, and to the already observed trend towards an ageing population.

In Italy, since the second post-war period, a first demographic transition has taken place around the 80s of the last century. During this first phase, processes of redefinition of social and identity roles, in addition to biological developments in terms of life expectancy, have marked a change in the stages of the creation of the family. A second alteration has followed which upset the traditional view of the parental model, also in response to the continuing negative economic situation. Households without a nucleus have determined a change from an archipelago structure multi-nuclear and multi-generational families - to an atoll structure - mono-nuclear or without nucleus and monogenerational families. Elderly people live today in familiar contexts with the following characteristics:

- a majority presence of «childless couples» up to the age of 84 ;

- a significant presence (19.9\%) of families with couple between the ages of 65 and 74 who still have children in the parental nucleus;

- families entirely composed of the elderly;

- a remarkable percentage of families composed of «lonely people» .

So, need of support from care institutions increases. Local services are responsible for health and social assistance, according to an organisational integrated scheme of collaboration (Pesaresi, Gori, 2003).

As regards the subject of this article, it is congruent to focus attention on residences for the elderly. It must be underlined that the offer appears to be diversified between public and private and distributed in the various territorial realities. Literature has emphasised that the political framework is very varied and irregular: service strategies are characterised by a high level of local differentiation and have an ambivalent nature:

"On the one hand, the literature on welfare federalism has stressed negative consequences in terms of potential veto points, especially at the subnational level. A federal welfare structure and a strong division of institutional responsibilities may discourage necessary reforms through cost-shifting between jurisdictions [...]. Decentralisation and welfare federalism may, on the other hand, ease the development and endurance of social programs. Local and regional authorities tend to be closer to the population and may be more receptive to social demands" (Arlotti, AguilarHendrickson 2017: 648).

Undoubtedly, the decentralisation process in favour of regions has led to a stratification of the interventions for which the strategies are inspired by national guidelines and developed in a multilevel perspective. The success of the implementation process is clearly conditioned by the economic and socio-cultural context.

In other words, social federalism can give life to «virtuous circles», "in which a clear attribution of responsibilities and resources among the different territorial levels of government take place, can allow for both coordination and local adequacy" (Arlotti 2017: 648), or to "vicious circles» with negative effects when the institutional framework is based on chaotic relations between service providers (Aguilar-Hendrickson \&Sabatinelli 2014).

Moreover, the economic-financial crisis has imposed policies of cost reduction on the Italian State, against an increase in the demand for help and support. Italian studies have shown a greater participation in spending by users or their families (Ranci\&Pavolini 2013; Fargion 2013).

\footnotetext{
${ }^{11} \mathrm{Cf}$. https://social.un.org/ageing-working-group/. In this perspective there is also the establishment of "Age Platform Europe" (https://www.age-platform.eu/) a network of non-profit associations that has the goal of creating an inclusive and equal society for all age groups.

${ }^{12} \mathrm{Cf}$. http://www.solimai.it/solimai/index.jsp?codicePagina=TAM.
} 
Unfortunately, the phenomenon cannot precisely be evaluated because the number of residences is not known; in this regard they are referred-to as "invisible" structures (Auser 2011). The legislator makes a generic reference to "residential and semi-residential services", without defining their contents. The National Guidelines distinguish between nursing homes (RSA - ResidenzeSanitarieAssistenziali), socio-health residential facilities and care homes (RA - ResidenzeAssistenziali), social-care residential buildings. The substantial difference concerns the level of protection they provide to recipients. The RAs are home to fully or partially self-sufficient elderly, whose health services are guaranteed by local health services. RSAs, indeed, are destined to non-self-sufficient elderly host and other individuals who therefore need continuous assistance. On the basis of these general guidelines, Italian structures have undergone a multifaceted development based on demand. The evaluation is strongly conditioned by different methods of classification that each Italian region decides to adopt. For example, the current denomination of RSA has taken on different meanings, with respect to retirement homes, protected homes, protected residences, geriatric rehabilitation institutes, long-stay rehabilitations, etc. If their identification is very uncertain, the data are practically non-existent due to the absence of a national information flow capable of constructing indices of the different social housing (social, health or healthcare) and evaluating the appropriateness of the treatment.

The following table (Tab. No. 1) shows the guests of the residential social-health facilities in 2015, distinguishing them in two groups: who receive assistance with financial commitment of the State and who personally bear the costs of admission .

The followingtable (Tab. No. 1) showstheguestsoftheresidential social-health facilities in 2015, distinguishingthem in two groups: whoreceiveassistancewithfinancialcommitmentofthe State and whopersonallybearthecostsofadmission ${ }^{13}$.

Tab. No. 1: Guests oftheresidential social-health facilities in 2015

\begin{tabular}{|l|l|l|l|}
\hline WHERE & $\begin{array}{l}\text { RESIDENTIAL UNITS } \\
\text { withpublicfinancing }\end{array}$ & $\begin{array}{l}\text { RESIDENTIAL } \\
\text { UNITS } \\
\text { nopublicfinancing }\end{array}$ & TOT \\
\hline North & 4.976 & 1.580 & 6.556 \\
\hline Centre & 1388 & 898 & 2286 \\
\hline South and Islands & 1.716 & 1.351 & 3.067 \\
\hline ITALY & 8080 & 3829 & 11909 \\
\hline
\end{tabular}

Source: Own elaboration on Istat (2015).

What needs to be underlined is the important difference in the public financial commitment between North and other areas of the peninsula: the number of patients in public facilities in the North is considerably greater than that of the Centre, of the South and the Islands. This information can be read following a double reasoning: on the one hand concerning the public institutional participation, which is more widespread and numerous in the northern area; on the other hand, concerning the family'stransformation for which in the South the parental network is presumed still active and attributable to the traditional model, very different from the northern one where the elderly population asks for support beyond the domestic walls. Observing the distribution of the guests with no public financing, the difference between North and South disappears: there are no significant divergences, even though there is a greater presence of people over sixty-five in Northern Italy. In this regard, it is useful to report a recent survey lead by the European Union of Cooperatives (Uecoop) ${ }^{14}$. It analyses the phenomenon of the diffusion of private retirement homes. The research shows a significant increase in these structures between 2006 and 2016 equal to $40 \%$ of beds. The progressive ageing of the population needs the creation of long-term assistance outside the perimeter of the family with the need to strengthen a coordinated welfare system, and sometimes with mixed management, of public and private:

"Retirement homes are becoming the new frontier of assistance with the record of almost 500 million euros invested last year by Italian and foreign companies (60\% of capitals are French) for sales of structures for the elderly mainly in the North and Central part of Italy between Lombardy, Piedmont, Lazio and Tuscany [...] A boom with the creation of new beds, which in the private sector have gone from 159,851 in 2006 to 223,800 in 2016, with a positive balance of almost 64,000 against which, however, we are witnessing a drop of almost $15 \%$ in the public sector and the loss of over 15,700 beds. In this way, comparing the two sectors, 7 beds out of 10 are privately managed" (Uecoop, 2018: 1).

In respect of a meeting mechanism between a servicedemand and supply, increase of the first is followed by expansion of the second. It should be noted that this takes place in a regulatory system and that it is the product of a consolidated

\footnotetext{
${ }^{13}$ The survey on residential social welfare facilities, provided for by the national statistical program in force (IST 00243) starting from 2010, expands its information contents, adapting them to the cognitive needs linked to the social-health integration process. Cf. http://dati.istat.it/Index.aspx?QueryId=21803\#.

${ }^{14} \mathrm{Cf}$. https://www.sistan.it/index.php?id=68.

12
} 
regionalisation: each Italian Region ${ }^{15}$ regulates an authorisation procedure and an accreditation system. Permission is required to activate the services. Accreditation is intended to guarantee quality of assistance and concerns structures, technologies and professionals employed. All the subjects must be accredited.

\section{The activity of the Guarantor: a research on the first three years.}

It is clear that there are many factors of change in the care assistance system: transformations in the network of the supportive family, ageing of the population and diversification of the care offer. In particular, the latter becomes the link between the care institutions and the controlling role of Guarantor. Public and private actors are services providers but they use different languages and practices which should meet a common point at the end of the authorisation and accreditation procedure. However, even if the latter is regulated, it does not guarantee that works are suitable to the users' needs and that they do not generate abuse'scases.

For these reasons, the legislator has felt the urgency to monitor care activities in residences focusing on strategies to prevent discriminatory behaviours towards those people who are socially and physically fragile. NGDL supervisory action must be interpreted in this perspective of caution perspective towards situations potentially connected with ageism. To this end, it will be analysed through two different points of view: on the one hand, by examining the contents of the three reports presented so far to the Italian Parliament; on the other, observing how many visits have been made, in which structures and whether they have given rise to recommendations or warnings.

\section{1: Reports to the Parliament.}

In the first report of 2017, the Guarantor expresses his desire to monitor the places of care and invites to think about the use of restraint tools: it cannot be justified by the installation of video surveillance circuits, but it must always take place under the medical supervision; moreover, he considers as a priority the establishment of a mechanism able to continuously monitor structures (publicand private) also through the contractual regulation which must clearly point out responsibilities and contents of the care provision.

Guarantor intends to proceed with controls and to prepare guidelines that take into account various aspects:

$\gg$ structure (surface, number of guests, architectural barriers, outdoor spaces, access to services);

$>$ organization (human resources management; operators'number with respect to guests and assistance time; guarantee of the right to self-determination; operators-rotation, training courses and turnover rules - and regarding to the guests' needs - food's personalisation, visiting hours, possibility of outdoor access or to religious services);

$>$ health care and assistance (medical consultations, preparation of medical records, presence of nursing staff, compliance with accident protocols, protocols relating to physical restraint).

In the subsequent document of 2018, NGDL claims the need for mapping residences for the elderly as a central passage of monitoring and prevention of improper forms of contraction. The theme of the restraint use, both physical and chemical or environmental, is essential and it must fully respect the integrity of the guests as it is a:

"Kind of places where institutionalisation and segregation can be generated as a de facto condition following a voluntary entry, as a consequence of the loss of the capacity for self-determination or of the supportive family references, assuming the characteristics of exposure to the risk of violations of the integrity of the rights of the person "(NGDL, 2018: 155).

The Guarantor interest is aimed to avoid that elderly people have to reside against their own will. This can happen when, after voluntary access and after having already completed a long-term path, they are de facto obliged to remain within the structure, having no other possibility for different reasons: "The freedom of self-determination can be denied even in the most ordinary gestures of daily life. In fact, in most cases, structures follow a rigid timetable: wake, meals (with a maximum duration) and rest.

Pre-established programs deprive guests of the liberty to live according to their own rhythms and habits. In almost all cases, they are justified because they are linked to the organisational needs of the staff "(NGDL, 2018: 157).

From the international bodiesexperience, as the European Committee for the Prevention of Torture and Inhuman or Degrading Treatment or Punishment $(\mathrm{CPT})^{16}$, positive relationship between the institutionalisation'process and liberty'sdeprivation represent a real hypothesis to explain those cases in which the autonomy'spromotion is not supported:in fact, the predominantly medical character of the structure, combined with static and standardised services, can increase the risk of limiting one's liberty.

\footnotetext{
${ }^{15}$ Legislative Decree 18 August 2000, n. 267, Consolidation text of the laws on the regulation of local authorities, retrieved from https://www.gazzettaufficiale.it/eli/id/2000/09/28/000G0304/sg.

${ }^{16} \mathrm{Cf}$. https://www.coe.int/en/web/cpt.
} 
Together with two Italian research university centres ${ }^{17}$, Guarantor started a research on indicators of limiting freedom, but it has not been completed yet. Certainly, it is a complex operation that presents various difficulties. First of all, there is a definition's confusion: care facilities for people with disabilities or elderlyare described uniforming fragility situations, althoughprofoundly heterogeneous. This obscures the analytical perspective. When Guarantor highlights the absence of a structures map and their systematisation, he ends by assembling the discrimination and ill-treatment mechanisms towards elderly and disabled people. Another factor of complexity is related to the services regionalisation: this fact has prevented a uniform classification throughout the national territory and has determined the diversification of the accreditation procedures criteria. The large number of typologies, only partially coincident and comparable on a regional basis, has provoked confusing effects also on the validity of the Interregional Social Services Nomenclator; this is an information device and it should provide a common language, determine essential levels of social assistance and allow the comparison on homogeneous items among the different regional welfare systems ${ }^{18}$. It is not so: the Nomenclator appears to be unreliable in order to identify the structures to visit.

\section{2: Visits to the structures.}

An interesting point concerns the NGDL faculty to visit care structures and for which there is no obligation to give prior notice. Here we want to draw attention to a double semantic dimension of the inspection: the one relating to the place seen as a setting for socialisation which assumes relevance as a potential arena of discriminatory mechanisms; the one concerning the persistent predominance of the penal area over the health one that can be evaluated by the number of visits carried out in both.

Hervé Clerc affirms that: "To find the pearls [...] it is not enough to look at the sea, you have to dive into it" (2018: 32); it is possible to observe practices and see fragilitiesonly through visits:"Places, life contexts, are fundamental elements to allow people to define their role and find their social identity. People grasp symbolic meanings through them and establish relationships with each other and with the place itself. Because places express meanings, define status, determine functions. Their organisation and management are able to change the life of a person, they can produce discomfort or, on the contrary, inclusion; they can favour development or lead to apathy and discouragement"(NGDL, 2019: 52).

As regards organisational model, the NGDL denounces the prevalence of a medical logic, similar to a hospital:"Indistinctly between accommodation facilities for guests whose presence can be temporary and short, and those prepared for a long presence and, in some circumstances even definitive, most of them are made following the architecture of a real hospital ward. This is designed as a place separate from other locations, with residual outdoor spaces and, in some cases, made from the reconversion of unused spaces"(NGDL, 2019: 87).

To understand the title for which the person is hosted in a residenceit is useful to explain that: the source of the socialhealth service changes according to the structure in which it will be performed. If it is a private structure, the contract with which the old person is taken in charge will be valid on the basis of the medical commission report; in this case the relationship has a private nature and is governed by civil law. If the service is public or private one in agreement with the NHS(the «longa manus» of public administration), it has a publicistic nature and its source is in regional laws and in agreement; in this case the relationship is governed by public law (Padua Court 560/2018). But how many visits has the supervisory body carried out in Italy since its establishment? And what structures has he visited? The following table (Tab. N.2) shows the frequency (in absolute terms) of the inspections in the years 2016, 2017, and 2018, as indicated in the reports delivered to the Parliament ${ }^{19}$.

\footnotetext{
${ }^{17}$ L'Altrodiritto - Inter-university Research Centre on Prison, Marginalisation and Migration Governance (cf. http://www.adir.unifi.it/index .htm) and the Robert Castel Centre for Governmentality and Disability Studies (CeRC, cf. https://www.unisob.na.it/ateneo/c007_a.htm?vr=1).

${ }^{18} \mathrm{Cf}$. http://www.regioni.it/upload/DOCCRP10)NOMENCLATORE_SERVIZI_SOCIALI.pdf.

${ }^{19} \mathrm{Cf}$. http://www.garantenazionaleprivatiliberta.it/gnpl/it/pub_rel_par.page

14
} 
Tab. No. 2: NGDL Fields and Inspections (2016-2018)

\begin{tabular}{|l|l|l|l|l|}
\hline FIELDS & $\mathbf{2 0 1 6}$ & $\mathbf{2 0 1 7}$ & $\mathbf{2 0 1 8}$ & TOT \\
\hline MIGRANTS & 15 & 36 & 38 & $\mathbf{8 9}$ \\
\hline $\begin{array}{l}\text { PENAL } \\
\text { (Adults and minors) }\end{array}$ & 40 & 40 & 42 & $\mathbf{1 2 2}$ \\
\hline $\begin{array}{l}\text { POLICE STATION AND } \\
\text { HEADQUARTER }\end{array}$ & 14 & 19 & 11 & $\mathbf{4 4}$ \\
\hline REMS $^{20}$ & - & 4 & 4 & $\mathbf{8}$ \\
\hline $\begin{array}{l}\text { PROTECTED MEDICIN } \\
\text { REPART AND TSO }\end{array}$ & - & 10 & 12 & $\mathbf{2 2}$ \\
\hline $\begin{array}{l}\text { DISABLED AND ELDERLY } \\
\text { REHABILITATION AND } \\
\text { RESIDENTIAL CENTRES }\end{array}$ & - & 2 & 16 & $\mathbf{1 8}$ \\
\hline TOT & 69 & 107 & 120 & 303 \\
\hline
\end{tabular}

Source: Reports NGDL 2017, 2018, 2019.

Some explanations will be useful: every field implies different places inspected. With regard to those pertaining to this essay, it is necessary to make two observations:

1. the creation of a unique group "disabled and elderly rehabilitation and residential centres" is due to the lack of precise indications on the type of visited structure;

2. No visit to a residence for the elderly or disabled is reported for the year 2016.Moving on to the analysis of information, a clear predominance of inspections in the penal area and in that of migrants is evident.

In 2017 , there have been very few visits to the structures for the elderly or disabled, but they increase, in a very significant way, in 2018. In fact, from two inspections carried out in 2017 (in Cremona and Salerno), we move to 16, covering the various areas of Italy and affecting different structures: communities, rehabilitation centres, retirement homes and foundations. The 2017 inspections concerned the hospital Foundation - Sospiro Disabled Units and the "La Pagliuzza" therapeutic-rehabilitation community; the first offers assistance to those who are in a state of disability; the second is addressed to those who suffer from pathological addiction, drugs or alcohol. So, none of the two visits is relevant to our investigation.

Differently, in 2018, 6 visits out of a total of 16, involved nursing and care homes for the elderly. In detail, these are two retirement homes in Corato (in the province of Bari) of the Oasi Nazareth Foundation and "Padre Pio" in Catania, of the RSA "Arka" also in Catania, of the Care Centre for the Elderly "Maria Regina" in Sant'Agata li Battiati (in the province of Catania), of the House of the elderly "Saint Lucia" in Augusta (province of Syracuse) and of the "Nardacchione" cooperative in Casacalenda (province of Campobasso). Controls concerned private structures that are located in the south of Italy and that provide assistance in agreement with the NHS.It should be noted that in no case neither in 2017 nor in 2018 - the NGDL has produced warnings or recommendations. This means that no risk of discrimination or ill-treatment has been detected against the elderly guests.In conclusion, the number of visits is in itself modest, especially when compared to that concerning the penal and migrant areas. However, it can reasonably represent an important turning point for the development of a supervisory action. Certainly, it is fundamental to invest resources and energy on the basis of shared definition's criteria. In the absence of this, the activity of the NGDL is slowed down and perceived as occasional and not systematic.

\section{The «external, but collaborative, eye»}

The title of this paragraph is taken from the report 2018. It was chosen because it summarises the idea that the independent authority has about its role in the Italian legal system. The reading of the reports and the observation of his activity return a picture that is not really complete. So far, in fact, various deficiencies have emerged. The defining criteria of the reception facilities in question are not univocal in the various Italian regions; this determines a fragmentation of the care offer that prevents the NGDL from proceeding first of all to a serious and precise mapping and, therefore, to a completecontrol action of the structures. In 2018, some actions were performed but it is still too little. This should not sound like a criticism, but rather as a reminder of its social relevance and its importance as an institution of prevention. The guaranteeing body is composed of competent people with specialised cultural resources; this assures a privileged approach different from the typical of public administration.

\footnotetext{
${ }^{20}$ Acronym REMS refers to the Italian institution in which the detention security measures are carried out.

${ }^{21}$ Acronym TSO refers to the Italian mandatory medical treatment.
} 
Guaranteeing authorities exercise, exclusively or predominantly, attributions qualitatively different from the traditional public ones. They go beyond the limits of the state administrations thanks to their independence, "since, with them, the umbilical cord of the derivation from the executive is not limited to lengthening, but it completely breaks" (Amato, 1998: 380). This presumes that the institutional context respects the "pluralist" (Bin, 2002: 122) nature of the Italian Constitution. In this way it removes all the doubts regarding the alleged violation of the principle of separation of powers: the Guarantor, with its own expertise, legitimately carries out control activities to protect the community, without its action being perceived as an attempt to interfere in the management of public «affairs». Moreover, it could promote the spread of good administrative practices and initiatives to redefine problems by putting the language of rights at the centre of the debate.

It is clear that it is necessary to «observe» living conditions and treatments in order to prevent possible abuses and offences of dignity. In this way, the supervising power becomes fundamental also in its unpredictability and informality. In other words, it seems that his harmlessness allows him to move in institutional relations in an autonomous and free manner in respect of his mandate. Consequently, this profile must be strengthened, even more taking into account the fact that sometimes institutions got caught unprepared (above all those that provide socialhealth assistance to the elderly), because they are not used to the possibility of being controlled by an independent body and that are not perceived as places of deprivation of liberty. This can generate suspicion and closure:"It was not always easy to enter them: sometimes the barrier constituted by the care and non-custodial purpose of the host structure was interposed. However, the Guarantor asks to include in the set of the requisite for the accreditations of private institutions the forecast of such visits and the commitment to favour them: this in order to avoid delays in the access to the structures "(NGDL, 2019: 12).

Clearly, «contractually» forbidding accredited residences to hinder the visit of the NGDL would represent a very important step for the recognition of the vigilance role but also of institutional collaboration. In a process of "cultural maturation" (NGDL, 2018: 36), although slow, the control of structures, aimed at the ageism prevention, becomes a central instrument for protecting human frailties and weaknesses that would otherwise remain obscure to the judicial authorities. For this reason, it has been designated as an international mechanism to prevent torture. The conviction that human security can be pursued by protecting and making effective human rights (Ballesteros, 2008), especially those who are in conditions of physical and mental fragility such as the elderly, is now a common heritage. International precepts: "impose lines of behaviour, demand actions of a certain type to the governments" (Cassese, 2009: 4).

If the NGDL has the mandate to place its action in this broad cultural and political perspective, it is necessary to remove those institutional obstacles that could prevent it from taking place. So, the Regional fragmentation of care provision produces uncertainty regards explanation of the contents of the service. Taking into account that "in international law the State appears in its unity and not in its administrative partitions" (Lattanzi, 2018: 59), univocal parameters and procedures are now fundamental to favour a timely residences recognition also through the analysis of conventional or regulatory documents that govern the hosting relationship. Such negligence could seriously damage patients and guests whose protection could be irretrievably compromised and unknown to the judicial authorities if even the NGDL is not allowed to protect them from the risk of ageism.

\section{References}

Aguilar-Hendrickson M. \&Sabatinelli S. (2014). Changing Labor Markets and the Place of Local Policies. In Ranci C., Brandsen T. \&Sabatinelli S. (Eds). Social Vulnerability in European Cities (pp. 67-102). Basingstoke and New York, NY: palgrave Macmillan.

Amato G. (1998). Le autorità indipendenti, in Violante L. (Ed.). Storia d'Italia. Legge, Diritto, Giustizia Torino: Einaudi.

Arlotti M.\& Aguilar-Hendrickson M. (2017). The Vicious Layering of Multilevel Governance in Southern Europe: The Case of Elderly Care in Italy and Spain. Social Policy \& Administration, 52: 646-661.

Doi: $10.1111 /$ spol.12351.

Auser (2011). Indagine sulle case di riposo in Italia. Risultati principali. Retrieved from http://images.auser.it/f/casediriposo/sl/slidecaseriposo.pdf.

Ballesteros J. (2008). Sicurezza umana e indivisibilità dei diritti. Ragionpratica, 30, 1: 13-25. Doi: 10.1415/26944.

Barber S.J. \& Tan S.C. (2018). Ageism Affects the Future Time Perspective of Older Adults. GeroPsych, 31(3): 115126. Doi: $10.1024 / 1662-9647 / \mathrm{a} 000189$.

Bin R. (2004) Lo stato di diritto, Il Mulino Bologna.

Idem (2002). Ragionevolezza e divisione dei poteri. in Diritto \& questioni pubbliche, 2: 115-131. 
Brothers A., Chui H. \& Diehl M. (2014). Measuring Future Time Perspective Across Adulthood: Development and Evaluation of a Brief Multidimensional Questionnaire. The Gerontologist, 54: 1075-1088. Doi: 10.1093/geront/gnu076.

Brothers A., Gabrian M., Wahl H.W. \& Diehl M. (2016). Future Time Perspective and Awareness of Age-related Change: Examining Their Role in Predicting Psychological Well-being. Psychology and Aging, 9: 243-246. Doi: 10.1037/pag0000101.

Butler R. N. (1975) Why Survive? Being Old in America, Harper \& Row, New York.

Cassese S. (2009) I diritti umani oggi. Gius. Laterza \& Figli, Bari.

Clerc H. (2018). A Dio per la parete nord. Milano: Adelphi.

Cortijo V., McGinnis L.P.\&Şişli-Ciamarra E. (2019). The AGE Model: Addressing Ageism in the Workplace Through Corporate Social Responsibility. Labor and Society, 22: 197-213.

Di Rosa M., Chiatti C., Rimland J.M., Capasso M., Scandali V.M., Prospero E., Corsonello A.\& Lattanzio F. (2018). Ageism and Surgical Treatment of Breast Cancer in Italian Hospitals. Aging Clinical and Experimental Research, 30: 139-144.

Evans C.H.\&Montvillo R.K. (2018). Ageism. Encyclopedia of Health, Salem Press.

Eurostat. (2018). Struttura e invecchiamento della popolazione, https://ec.europa.eu/eurostat/statisticsexplained/index.php?title=Population_structure_and_ageing/it\#Tendenze_passate_e_future_dell.27invecchiam ento_della_popolazione_nell.27UE.

Fargion V. (2013). Le politiche per la non-autosufficienza. In Fargion V. \& Gualmini E. (Eds.), Tra l'incudine e il martello: regioni e rischi sociali in tempo di crisi (pp. 37-71). Bologna: Il Mulino.

National Guarantor for the rights of people detained or deprived of their liberty (2019), Relazione al Parlamento 2019, http://www.garantenazionaleprivatiliberta.it/gnpl/resources/cms/documents/00059ffe970d21856c9d52871fb31 fe7.pdf .

Idem (2018a), Relazione al Parlamento 2018, http://www.garantenazionaleprivatiliberta.it/gnpl/resources/cms/documents/29e40afbf6be5b608916cad716836 dfe.pdf .

Idem (2018b), Libertà e salute, http://www.garantenazionaleprivatiliberta.it/gnpl/resources/cms/documents/c801a77dd4d02876b080fb0ce8e46a d94.pdf .

Idem (2017), Relazione al Parlamento 2017, http://www.garantenazionaleprivatiliberta.it/gnpl/resources/cms/documents/91f69ffca2d0d1e224c08c65adf623 43.pdf .

Kennedy M.J.\&Montvillo R.K. (2000). "Effects on Age and Contact on Attitudes toward Aging and the Elderly". Gerontologist, 40: 147.

Lattanzi F. (2018). Accountability, pp. 54-59. http://www.garantenazionaleprivatiliberta.it/gnpl/resources/cms/documents/29e40afbf6be5b608916cad716836 dfe.pdf.

Levy S.R. \& MacDonald J.L. (2016). Progress on Understanding Ageism. Journal of Social Issue, 72: 5-25. Doi: 10.1111/josi.12153.

Migliaccio J. N. (2019). The Ageism Within and How to Counter It. Journal of Financial Service Professionals, 73(2): 26-31.

Palmore E. (1999). Ageing: Negative and Positive. 2nd Ed., New York: Springer.

Pesaresi F.\& Gori C. (2003) "Servizi domiciliari e residenziali per gli anziani non autosufficienti in Europa", Tendenze nuove, n. 4-5, 433-

Ranci C. \&Pavolini E. (2015). Le politiche di welfare. Il Mulino: Bologna.

Ranci C. \&Pavolini E. (Eds.) (2013). Reforms in Long-term Care Policies in Europe: Investigating Institutional Change and Social Impacts. New York, NY: Springer.

Raymer M., Reed M., Spiegel M. \&Purvanova R.K. (2017). An examination of Generational Stereotypes as a Path Towards Reverse Ageism. The Psychologist Manager Journal, 20(3): 148-175. Doi: 10.1037/mgr0000057.

Tribunale di Padova (2018), II sezione civile sentenza 12/03/2018 n. 560. https://www.mtdonlus.org/home/pdf/altri/TOR\%20PD\%2018-00560.pdf.

Uecoop (2018). Case riposo: 1 posto letto per 41 anziani, http://www.uecoop.org/case-riposo-uecoop-1-posto-lettoper-41-anziani/. 